\title{
Stage I Nasopharyngeal Undifferentiated Carcinoma AJCC v7
}

National Cancer Institute

\section{Source}

National Cancer Institute. Stage I Nasopharyngeal Undifferentiated Carcinoma A/CC v7. NCl Thesaurus. Code C8223.

Stage I includes: T1, N0, M0. T1: Nasopharyngeal cancer with tumor confined to the nasopharynx, or tumor extending to oropharynx and/or nasal cavity without parapharyngeal extension. Parapharyngeal extension denotes posterolateral infiltration of tumor. N0: No regional lymph node metastasis. MO: No distant metastasis. (AJCC 7th ed.) 